
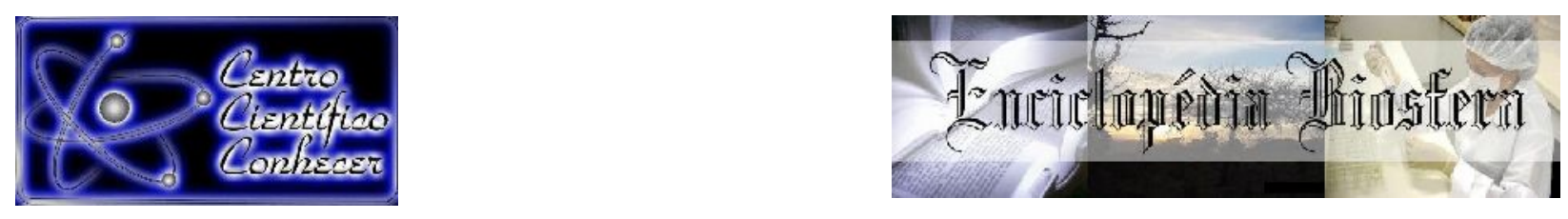

\title{
MAPEAMENTO DO USO DAS TERRAS DA SUB-BACIA HIDROGRÁFICA DO RIBEIRÃO SANTO AMARO, NO SUL DO ESTADO DO ESPÍRITO SANTO
}

\author{
Caio Henrique Ungarato Fiorese ${ }^{1}$, Wenderson Abreu Rosa Nascimento ${ }^{2}$ \\ ${ }^{1}$ Graduando em Engenharia Ambiental pelo Centro Universitário São Camilo, \\ Cachoeiro de Itapemirim, Espírito Santo, Brasil. (caiofiorese@hotmail.com). \\ ${ }^{2}$ Mestrando em Agroquímica pela Universidade Federal do Espírito Santo, Alegre, \\ Espírito Santo, Brasil. \\ Recebido em: 06/04/2019 - Aprovado em: 10/06/2019 - Publicado em: 30/06/2019 \\ DOI: 10.18677/EnciBio_2019A84
}

\begin{abstract}
RESUMO
A avaliação do uso e cobertura do solo de determinada bacia hidrográfica é um importante alicerce no que diz respeito à qualidade ambiental e de vida. Diante dos impactos ao meio ambientes provocados pela ação antrópica, o objetivo desta pesquisa foi analisar o uso de solo da sub-bacia hidrográfica do ribeirão Santo Amaro, no Sul do estado do Espírito Santo, bem como a distribuição das classes ao longo da área. Junto ao GEOBASES/ES, foram coletados arquivos, em formato shapefile, referentes às curvas de nível do local estudado para, posteriormente, gerar um Modelo Digital de Elevação no programa ArcGIS®. Através dos recursos do Arc Hydro Tools, foi delimitada a sub-bacia. No GEOBASES/ES, foram coletados dois arquivos de uso de solo referente ao mapeamento realizado nos anos 20072008 e 2012-2015 para o estado. Ambos foram recortados para o local estudado no ArcGIS® para identificar e quantificar as classes e, através da literatura e de registros fotográficos, interpretar os resultados. Há maior predominância de pastagens (aproximadamente 35\%) que, todavia, reduziu em 3\%. A silvicultura do eucalipto teve crescimento de $2,5 \%$ e os cultivos de café, presentes em pequenas propriedades e sob monocultivos, tiveram uma redução de $1 \%$. A floresta nativa esteve muito fragmentada em boa parte da região e, aliada a áreas de macega, revelou um problema quanto ao manejo de solo local. Ações de mitigação e atenuação dos impactos ambientais advindos principalmente da agropecuária e silvicultura do eucalipto nesta microbacia se fazem necessárias.
\end{abstract}

PALAVRAS-CHAVE: Geoprocessamento; Impactos Ambientais; Medidas Mitigadoras.

\section{MAPPING OF THE USE OF THE LANDS OF THE RIBEIRÃO SANTO AMARO HYDROGRAPHIC SUB-BOWL, SOUTH OF THE STATE OF ESPÍRITO SANTO}

\begin{abstract}
The assessment of land use and coverage of a given river basin is an important foundation for environmental and life quality. Considering the impacts to the environment caused by anthropogenic action, the objective of this research was to analyze the soil use of the sub-basin of the Santo Amaro river in the south of the state of Espírito Santo, as well as the distribution of classes along of the area.
\end{abstract}


Together with GEOBASES/ES, the files were formatted in the shapefile format, referring to the level curves of the study site and later to generate a Digital Elevation Model in the ArcGIS $\AA$ program. Through the resources of Arc Hydro Tools, the subbasin was delimited. In GEOBASES/ES, two land use files were collected referring to the mapping carried out in the years 2007-2008 and 2012-2015 for the state. Both were cut to the location studied in ArcGIS® to identify and quantify the classes and, through the liteerature and photographic records, interpret the results. There is a greater predominance of pastures (approximately 35\%) which, however, reduced by $3 \%$. Eucalyptus silviculture grew $2.5 \%$ and coffee crops, present in small farms and under monocultures, had a $1 \%$ reduction. The native forest was very fragmented in a large part of the region and, together with areas of macega, revealed a problem of local soil management. Actions to mitigate and mitigate environmental impacts resulting mainly from eucalyptus agriculture and forestry in this watershed are necessary.

KEYWORDS: Geoprocessing; Environmental impacts; Mitigating Measures.

\section{INTRODUÇÃO}

O crescimento urbano desordenado e sem um planejamento correto tem acarretado, em muitas situações, uma série de problemas no que tange o desenvolvimento funcional e no uso e ocupação do espaço. A apropriação da sociedade sobre o meio natural na busca de recursos para suprir suas necessidades transforma esse local em uma paisagem construída, em detrimento à vegetação nativa (SILVA, 2015). Apesar dos avanços tecnológicos e científicos, a gestão sustentável dos solos é uma grande tarefa para a sociedade, sendo que é cada vez maior a quantidade de espaços que atingiram seu limite de capacidade produtiva (FLAUZINO et al., 2016).

Melo et al. (2014) conceituam bacia hidrográfica como sendo um conjunto de terras drenadas por um rio principal e seus afluentes. O solo dessas áreas, ainda segundo os mesmos autores, tem como importância abrigar todos os elementos bióticos e abióticos. Segundo Di Mauro et al. (2017), a bacia hidrográfica é a melhor unidade territorial para haver um planejamento dos recursos hídricos, sendo que as organizações de atividades de produção, conservação ambiental e outros devem levar em consideração a bacia hidrográfica para ações de melhor gestão e ordenamento territorial. O manejo de bacias hidrográficas, relacionado ao uso e ocupação do solo e associado às características das mesmas, pode afetar significativamente na geração de sedimentos que, por sua vez, modificam a qualidade e quantidade de água dos recursos hídricos (APARECIDO et al., 2016), sendo que os processos de ocupação humana abrangem questões socioeconômicas, institucionais, políticas e ambientais (BELIZÁRIO, 2016).

O mapeamento multitemporal das classes de uso de solo de determinada região é um fator crucial para compreender os efeitos dos impactos antropogênicos sobre a vegetação florestal e outros biomas brasileiros (COSTA; BEZERRA; OLIVEIRA, 2017). De acordo com Oliveira, Acorsi e Smaniotto (2018), estudos em nível de microbacia hidrográfica podem permitir a obtenção de informações relevantes quanto ao manejo correto e diagnóstico dos problemas locais. Romão et al. (2017) destacam que estudos dessa natureza são relevantes na geração de medidas de mitigação da redução do desmatamento de florestas nativas, contribuindo, também, na conscientização do uso correto das terras.

Os chamados Sistemas de Informação Geográfica (SIG), segundo Coutinho (2015), representam a categoria de softwares específicos para espacializar, tratar e 
visualizar dados espaciais. Os SIG estão incluídos na área das geotecnologias, ou geoprocessamento que, de acordo com Bacani e Luchiari (2014), são um conjunto de procedimentos, técnicas e produtos que tratam da coleta dessas informações espaciais, oferecendo, assim, resultados precisos e importantes para diversas tomadas de decisões acerca de uma área em estudo. São também, segundo Donato e Magri (2017), essenciais na produção de mapas de uso do solo e degradação das chamadas Áreas de preservação Permanente (APPs), servindo como base importante no planejamento regional.

O objetivo desta pesquisa foi analisar o uso e cobertura das terras da subbacia hidrográfica do ribeirão Santo Amaro/ES, bem como propor medidas para melhorias da área e sugestões para futuros estudos.

\section{MATERIAL E MÉTODOS}

O local de estudo considerado foi a sub-bacia hidrográfica do ribeirão Santo Amaro (BHRSA), que fica localizada na mesorregião Sul do Estado do Espírito Santo. Esta área abrange parte dos municípios de Conceição do Castelo, Muniz Freire e Castelo, tendo a maior porção de suas terras em Muniz Freire. Possui $103,468 \mathrm{Km}^{2}$ de área de drenagem, e seu exutório fica localizado no rio Castelo, no município de Castelo/ES. A adoção desta microbacia se fez por ser uma área predominantemente rural, tendo a influência de atividades rurais impactantes negativamente ao meio natural. A Figura 1 mostra a localização da área.

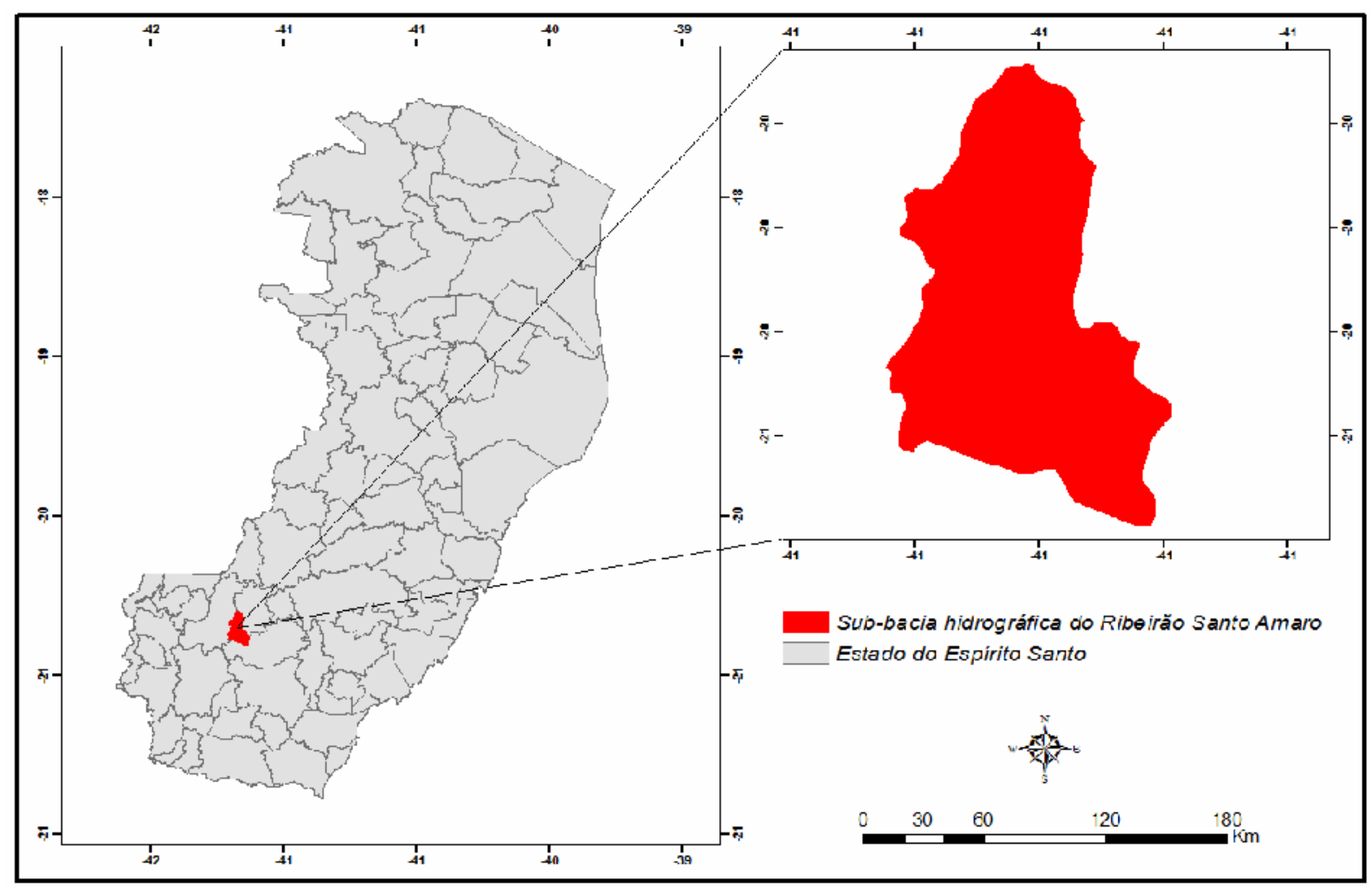

FIGURA 1. Localização da sub-bacia hidrográfica do Ribeirão Santo Amaro. Fonte: Os Autores (2019).

A base cartográfica considerada neste estudo foi o Sistema Integrado de Bases Geoespaciais do Estado do Espírito Santo (GEOBASES), que forneceu dois arquivos, em formato shapefile (.shp), acerca do uso e ocupação de solo no estado do Espírito Santo avaliado nos mapeamentos dos anos de 2007 a 2008 e 2012 a 2015, ambos feitos em escala igual ou superior a 1:25.000, segundo o Sistema. ENCICLOPÉDIA BIOSFERA, Centro Científico Conhecer - Goiânia, v.16 n.29; p. 1556 
Além disso, também foi consultado no GEOBASES os dados acerca das curvas de nível do local estudado, também em formato shapefile.

Foi utilizado, para manipulação dos dados, o programa computacional ArcGIS®, na versão 10.2.2. A princípio, foi gerado o chamado Modelo Digital de Elevação (MDE) para, posteriormente, delimitar toda a rede hidrográfica da região e a microbacia hidrográfica estudada, por meio dos recursos do Arc Hydro Tools, em versão compatível ao do ArcGISß. As etapas para delimitação da sub-bacia hidrográfica do Ribeirão Santo Amaro, desde a geração do MDE até o ícone batch point generation, são mostradas na Figura 2.

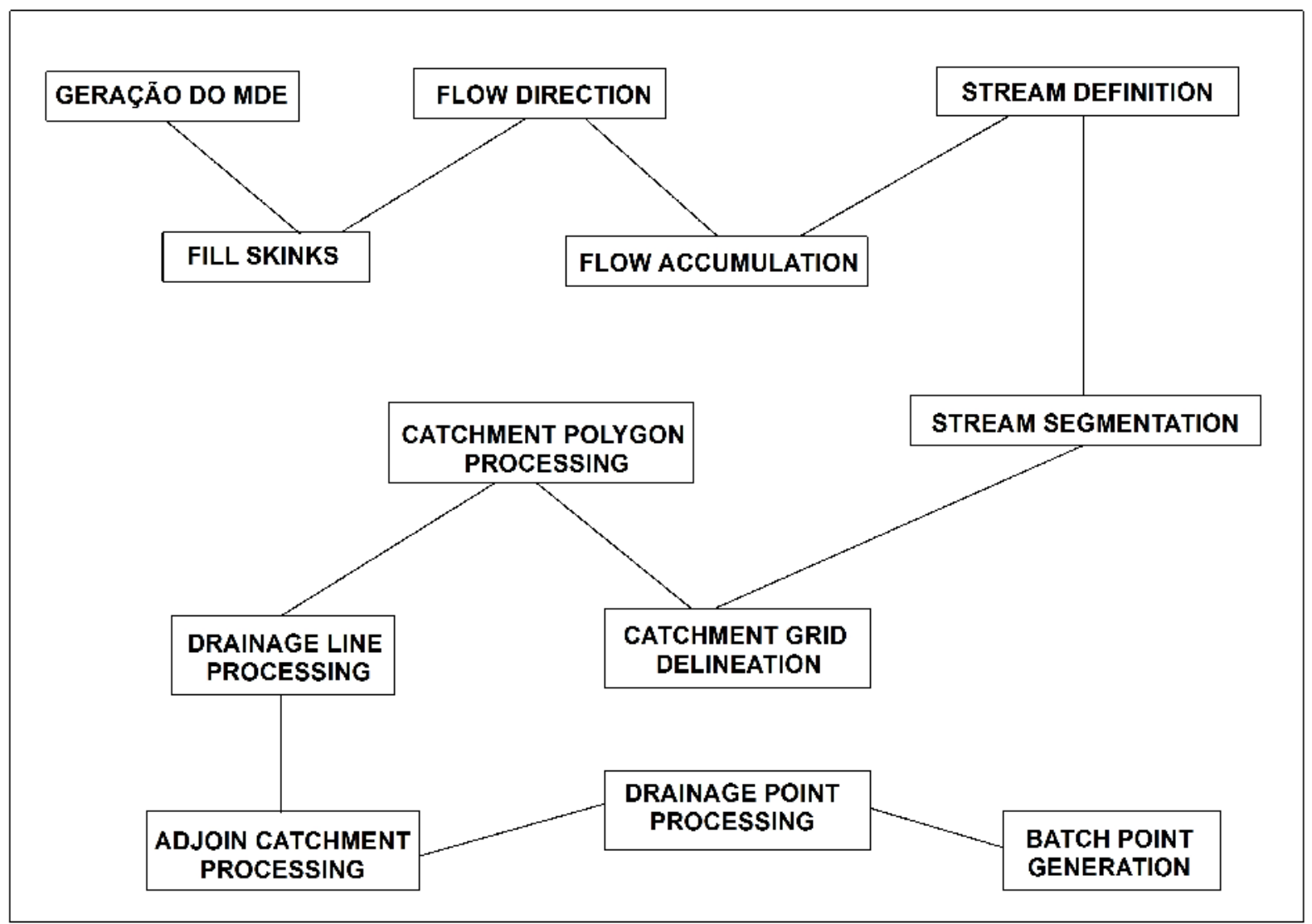

FIGURA 2. Esquema dos procedimentos de delimitação da sub-bacia hidrográfica do ribeirão Santo Amaro. Fonte: Adaptado de Processamento Digital (2015).

Com auxílio dos recursos de recorte (clip), cada arquivo de uso de solo foi recortado, delimitando, assim, as informações para apenas o local de estudo. A identificação das classes foi possível através da tabela de atributos e do ícone properties. Já a quantificação da área, em metros quadrados $\left(\mathrm{m}^{2}\right)$, de cada classe, foi feita através do recurso summarize na tabela de atributos.

O percentual de abrangência de cada classe de uso de solo foi estimado por meio da transferência das informações e estimativa dos valores em planilha do Microsoft Excel, relacionando a área de cada classe com a área total da microbacia. Os dados foram analisados a partir da representatividade de cada classe e conforme a potencialidade ou não de provocar impactos ambientais positivos ou negativos. As classes de uso de solo foram interpretadas e comparadas com base nos conhecimentos dos autores e na literatura, além de registros fotográficos feitos em alguns pontos in loco. 


\section{RESULTADOS E DISCUSSÃO}

Na sub-bacia hidrográfica do Ribeirão Santo Amaro, há grande variedade de classes de uso de solo, destacando-se a pastagem, com índices superiores a $35 \%$, a cafeicultura (percentuais em torno de $14 \%$ ) e a vegetação nativa consolidada (cerca de $20 \%$ ). A A macega e a mata nativa em estágio inicial de regeneração apresentaram, respectivamente, valores aproximados de $5 \%$ e $7 \%$. Tabela 1 mostra, com mais detalhes, a identificação e quantificação, em porcentagem (\%), das classes de uso e ocupação das terras da sub-bacia hidrográfica do ribeirão Santo Amaro.

TABELA 1. Classes de uso de solo, em percentagem (\%), referente aos mapeamentos dos anos 2007-2008 e 2012-2015.

\begin{tabular}{ccc}
\hline Classes & $\mathbf{2 0 0 7 - 2 0 0 8}$ & $\mathbf{2 0 1 2 - 2 0 1 5}$ \\
\hline Afloramento rochoso & 8,615 & 8,973 \\
\hline Área edificada & 0,059 & 0,047 \\
\hline Brejo & 0,117 & 0,113 \\
\hline Campo rupestre/altitude & 1,080 & 0,961 \\
\hline Cultivo agrícola - banana & 0,000 & 0,041 \\
\hline Cultivo agrícola - café & 14,146 & 13,113 \\
\hline Cultivo agrícola - cana-de-açúcar & 0,000 & 0,009 \\
\hline Outros cultivos permanentes & 0,307 & 0,661 \\
\hline Outros cultivos temporários & 0,812 & 0,349 \\
\hline Extração (mineração) & 0,006 & 0,035 \\
\hline Macega & 6,738 & 7,625 \\
\hline Massa d'água & 0,124 & 0,131 \\
\hline Mata nativa & 20,841 & 20,207 \\
\hline Mata nativa em estágio inicial de & 5,081 & 5,519 \\
regeneração & & \\
\hline Pastagem & 39,040 & 36,490 \\
\hline Eucalipto & 1,064 & 3,713 \\
\hline Solo exposto & 0,792 & 0,466 \\
\hline Outros & 1,178 & 1,547 \\
\hline
\end{tabular}

Há maior predominância de pastagens na sub-bacia estudada, com índices superiores a $35 \%$ em ambos os mapeamentos. Fato também observado em trabalhos semelhantes, como o de Melo et al. (2014) na sub-bacia hidrográfica do Rio Preto/AL e por Flauzino et al. (2016) na sub-bacia hidrográfica Piloto/MG. As atividades relacionadas à pecuária bovina de corte possuem grande destaque no Brasil, sendo o país com maior rebanho comercial e exportador do mundo e o segundo maior de bovinos (CARVALHO; DE ZEN, 2017).

Contudo, Paulino et al. (2012) alertam para os impactos ambientais provocados por essas áreas, que são, por exemplo: perda da cobertura vegetal, redução dos níveis de matéria orgânica do solo, compactação e carência de aeração do solo, escoamento superficial da água da chuva em detrimento à sua infiltração no solo e, até mesmo, maiores possibilidades de emissão de gases do efeito estufa. Impactos estes que foram visualizados na microbacia, principalmente no que diz respeito à presença de formações erosivas em áreas de pastagem como, por exemplo, sulcos e voçorocas. 
Durante a pesquisa in loco, foram verificados que há pontos de solo exposto, evidenciando, assim, um processo erosivo que atinge pastagens desta microbacia. Diante desse cenário, Bendito et al. (2017) indicam o diagnóstico ambiental como medida para mitigar os problemas ambientais das pastagens, bem como a recuperação dessas áreas através, por exemplo, da implantação dos Sistemas Agroflorestais (SAF's). Dessa forma, melhoraria a qualidade dos solos nas áreas de pastagens degradadas por meio do acréscimo de matéria orgânica e nutrientes, como o nitrogênio, além de servir como uma fonte de renda importante para os agricultores a partir da comercialização de frutos colhidos em Ssistemas Agroflorestais. Para a BHRSA, essa medida poderia ser viável em áreas abandonadas ou com manejo de solo mais incorreto, tornando a produção rural mais viabilizada e trazendo vários outros benefícios diante das grandes áreas de pastagem predominante nesta microbacia.

As áreas de mata nativa tiveram uma pequena redução neste período (em torno de $0,5 \%$ ), o que representa um risco quanto à qualidade ambiental da referida microbacia hidrográfica. Em compensação, a classe mata nativa em estágio inicial de regeneração aumentou em percentual muito próximo ao da redução da mata nativa, sendo, assim, um ponto positivo para a manutenção da vegetação florestal. Os fragmentos remanescentes de vegetação nativa, segundo Varjabedian (2010), devem ser protegidos de quaisquer perturbações, pois a mata atlântica, que abrange a sub-bacia hidrográfica do ribeirão Santo Amaro, é um dos mais importantes e ameaçados biomas do mundo.

As áreas de eucalipto tiveram aumento significativo (em aproximadamente $2,5 \%$ ) no período considerado, fato também observado em outros trabalhos, como o de Fiorese e Leite (2018). O estado do Espírito Santo, em escala nacional, representa $74,2 \%$ de área de eucaliptos em forma de monocultivos, ao passo que, a nível estadual, o eucalipto abrange $99,3 \%$ das áreas com monocultivo de árvores (LIMA et al., 2016).

Vital (2007) destaca o empobrecimento do solo em áreas cultivadas com eucalipto, contudo, afirma que essa cultura traz mais benefícios em relação a outros cultivos, como os de café e soja, no que diz respeito à biodiversidade, que é maior em relação às culturas supracitadas. Além disso, segundo o mesmo autor, o eucalipto serve de refúgio, casa ou ninho de várias espécies de pássaros. Diante da evolução da silvicultura do eucalipto, Moledo et al. (2016) destacam a importância de desenvolver um correto plano de manejo florestal no gerenciamento desse cultivo para, entre outros fatores, controlar os impactos ambientais provocados.

Entre os cultivos agrícolas, na região predomina a cafeicultura que, apesar da redução (em aproximadamente $1 \%$ de área), é um setor que se sobressaiu fortemente na região. Resultados similares aos obtidos por Fiorese e Leite (2018) em estudos acerca do uso de solo na sub-bacia hidrográfica do ribeirão Estrela do Norte, estimaram áreas de café em torno de 16\%, mas observaram que houve aumento dessas áreas. A cafeicultura, segundo Carvalho et al. (2016), há muito tempo é um produto de grande importância nas economias mundiais e no sustento de várias famílias, sobressaindo, assim, a chamada agricultura familiar, o que não é diferente na sub-bacia hidrográfica do ribeirão Santo Amaro. Apesar disso, o monocultivo de café é predominante na região da microbacia estudada, de acordo com as observações feitas in loco.

A cafeicultura brasileira desencadeou uma série de impactos sociambientais, como, por exemplo, o desmatamento da Mata Atlântica, perda de biodiversidade animal e vegetal, contaminação e degradação de cursos hídricos pela aplicação de 
agroquímicos, empobrecimento do solo e desequilíbrio ambiental (LOPES et al., 2014), necessitando, assim, de um correto manejo dessas áreas.

Zimmerman (2009) destaca que a monocultura é o cultivo de uma única espécie agrícola em certa região, mas esse modelo de cultivo agrícola é muito prejudicial ao solo devido à produção contínua da mesma planta (nesse caso, o café) e o uso indiscriminado de fertilizantes e agrotóxicos para combater as pragas, em função da uniformização dessa cultura. Diante desse cenário, a implantação dos chamados Sistemas Agroflorestais (SAFs) poderia ser uma medida a ser adotada por agricultores da sub-bacia hidrográfica do ribeirão Santo Amaro, com vistas a melhorar a qualidade da produção agrícola e dos elementos abióticos (água e solo, principalmente) necessários à agricultura, constituindo, assim, ganhos ambientais de grande importância.

As demais classes apresentaram áreas com percentuais relativamente baixos, entretanto, entre elas, destacam-se as formações rochosas, que representaram pouco mais de $8 \%$. A extração de rochas, apresar de ser uma atividade de forte destaque na região Sul do Espírito Santo, não é predominante na microbacia do ribeirão Santo Amaro, vide o percentual de área, que aumentou no período considerado.

Outra classe com percentual baixo, mas com certo destaque, é a macega, que aumentou em pouco mais de $1 \%$ de área. Dessa forma, evidencia um problema quanto ao manejo de solo dessa microbacia, pois as áreas de macega poderiam ser ocupadas sobretudo por vegetação nativa, obtendo, assim, maiores ganhos ambientais e, até mesmo, econômicos. As áreas edificadas ou construídas representaram percentual ínfimo (inferior a 1\%), concentradas no distrito de Vieira Machado, no município de Muniz Freire/ES, enfatizando, assim, a característica de uma bacia hidrográfica predominantemente rural. As Figuras 3 e 4 mostram a distribuição do uso de solo para a sub-bacia hidrográfica do ribeirão Santo Amaro referente aos mapeamentos dos anos 2007-2008 e 2012-2015, respectivamente.

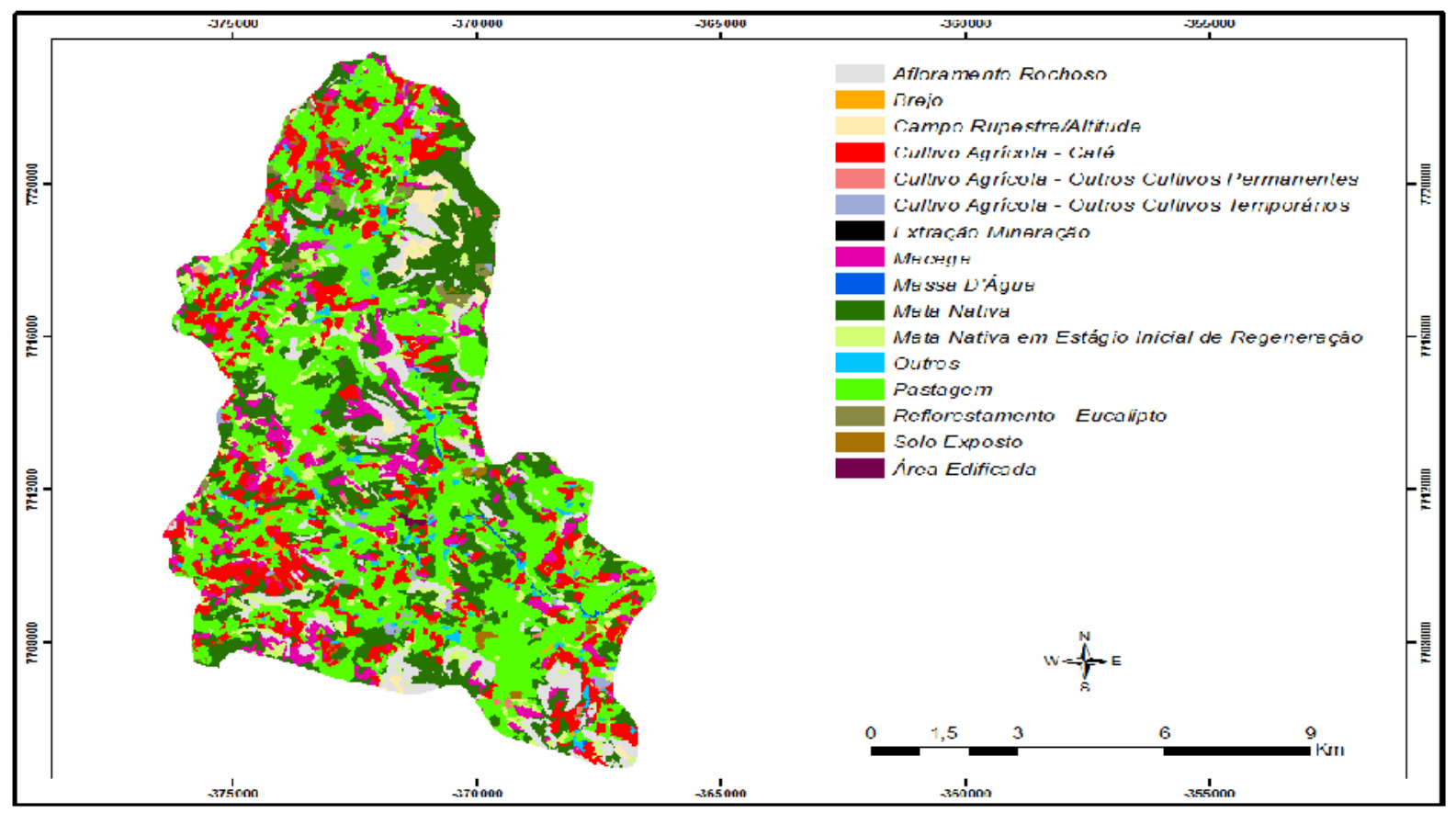

FIGURA 3. Uso de solo referente aos anos 2007-2008. Fonte: Os Autores (2019). 


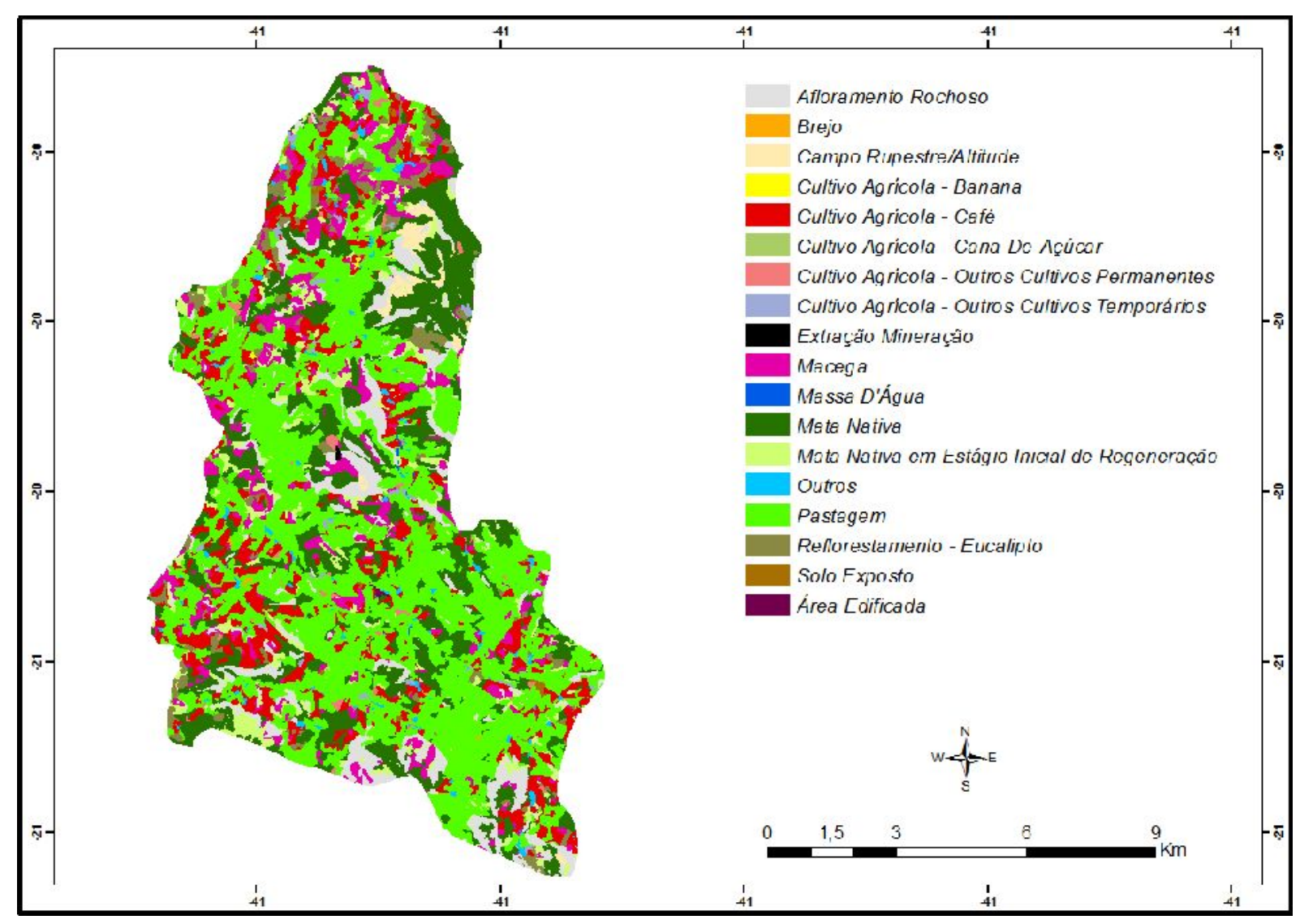

FIGURA 4. Uso de solo referente aos anos 2012-2015. Fonte: Os Autores (2019).

Conforme visto em ambas as figuras, há grande predominância de pastagens por toda a região. As áreas de mata nativa estiveram mais concentradas na direção nordeste da sub-bacia hidrográfica, todavia, nas demais áreas, estavam um tanto fragmentadas. A fragmentação florestal, de acordo com Lima et al. (2017), é um processo de subdivisão de áreas contínuas em manchas de variados tamanhos, provocadas por ação antrópica ou eventos naturais associados a mudanças do meio. Borges et al. (2004) destacam as consequências da fragmentação como, por exemplo, mudanças no microclima (umidade do ar, temperatura e radiação solar) principalmente nas bordas dos fragmentos, aumento dos riscos de erosão, assoreamento de corpos hídricos e diminuição do volume de água e maior possibilidade de predominância de espécies invasoras.

Os cultivos de café, em ambos os mapeamentos, estavam bem distribuídos em toda a área da bacia hidrográfica, devido, sobretudo, a predominância de pequenas propriedades na região. De acordo com o Incaper, $73 \%$ dos produtores do estado do Espírito Santo são de base familiar, vivendo em propriedades com tamanho médio de 8 hectares, sendo que a cafeicultura representa $35 \%$ do Produto Interno Bruto Agrícola capixaba.

A silvicultura do eucalipto ocorre, em maior escala, em áreas mais próximas à direção norte da microbacia e, inclusive, próximas a locais de mata nativa. As florestas plantadas, de acordo com Cedagro (2011), têm sido mais recomendadas em locais com baixa aptidão para outras atividades agrícolas, pelo fato de sobreviverem a condições naturais mais severas e protegerem melhor o solo. Além disso, as áreas de macega na sub-bacia hidrográfica do ribeirão Santo Amaro 
estavam bem distribuídas e concentradas, inclusive, próximas a fragmentos florestais, deduzindo, assim, um problema quanto ao manejo do solo dessas áreas.

No período analisado, não houve uma redução drástica das classes de uso e cobertura do solo, no entanto, ambos os mapas permitiram perceber a distribuição das formas de utilização das terras com maior nitidez e, até mesmo, prescrever alguns dos problemas ambientais enfrentados por esta microbacia hidrográfica. Diante desses problemas, se faz necessária a adoção de medidas de mitigação e atenuação dos impactos ambientais como, por exemplo, a rotação de pastos, utilização de leguminosas em consórcio com gramíneas (para fornecer nitrogênio à gramínea e, assim, melhorar a qualidade do solo), plantio direto e em curvas de nível e a construção de terraços (EMBRAPA, 2003). Essas técnicas, quando implantadas corretamente, poderão conter significativamente a erosão do solo oriunda do manejo incorreto da agropecuária nesta sub-bacia hidrográfica, juntamente com a ampliação da cobertura florestal nativa e a implantação de corredores ecológicos interligando fragmentos florestais (FIORESE; LEITE, 2018). Dessa forma, melhoraria significativamente a qualidade ambiental e de vida local, amenizando a ocorrência dos problemas ambientais mais graves.

De modo geral, as classes de uso de solo com maiores potencialidades de impactos ambientais na microbacia do Ribeirão Santo Amaro são a agricultura (principalmente a cafeicultura), a silvicultura do eucalipto, a pastagem e a vegetação nativa consolidada. A agropecuária e a silvicultura do eucalipto, conforme visto in loco, não estão sendo manejadas corretamente, em decorrência do aparecimento de formas erosivas no solo e da ausência de recursos de drenagem do escoamento superficial da água da chuva. Além disso, os percentuais de mata nativa consolidada e em estágio inicial de regeneração, embora não tenham apresentado redução significativa, poderiam abranger maiores áreas da sub-bacia do Ribeirão Santo Amaro, uma vez que as mesmas estão dispostas em fragmentos florestais na maior parte da sub-bacia, o que pode trazer consequências graves à fauna e flora locais. $O$ crescimento da macega e sua representatividade na sub-bacia estudada revelam um problema quanto ao manejo e planejamento dessas áreas, que poderiam ser mais bem reaproveitadas, assim como as áreas de pastagem.

De maneira geral, a sub-bacia do Ribeirão Santo Amaro se encontra degradada, devido ao emprego de técnicas de uso e planejamento do solo inadequadas e pela intensa ação antrópica decorrente da agropecuária e da silvicultura do eucalipto, resultando em grandes desafios quanto à preservação dos remanescentes florestais e sua conciliação com as atividades econômicas em expansão (no caso do cultivo de eucalipto) ou ainda em grande destaque.

\section{CONCLUSÃO}

Há maior predominância de pasto ao longo da bacia hidrográfica estudada, apesar de ter ocorrido uma redução dessa classe. A cafeicultura, presente em pequenas propriedades, teve uma queda, ao passo que a silvicultura do eucalipto apresentou bom crescimento e a redução das áreas de mata nativa foi compensada com o aumento de florestas nativas em regeneração.

Todavia, a fragmentação da floresta nativa, bem como a presença da classe macega próxima a esses fragmentos, indicam que a bacia hidrográfica enfrenta problemas quanto ao manejo e melhor utilização de suas terras, além de sofrer prejuízos quanto à biodiversidade e qualidade do meio natural, requerendo, assim, ações de mitigação e atenuação dos impactos ambientais advindos da agropecuária e silvicultura do eucalipto nesta sub-bacia. 


\section{REFERÊNCIAS}

APARECIDO, C. F. F.; VANZELA, L. S.; VAZQUEZ, G. H.; LIMA, R. C. Manejo de bacias hidrográficas e sua influência sobre os recursos hídricos. Revista Irriga, Botucatu, v. 21, n. 2, p. 239-256, mai./jun. 2016. Disponível em: <http://revistas.fca.unesp.br/index.php/irriga/article/view/1977>. https://doi.org/10.15809/irriga.2016v21n2p239-256

BACANI, V. M.; LUCHIARI, A. Geoprocessamento aplicado ao zoneamento ambiental da bacia do alto Rio Coxim-MS. Revista GEOUSP, São Paulo, v. 18, n. 1, p. 184-197, jan./abr. 2014. Disponível em: <http://www.revistas.usp.br/geousp/article /view/81098>. doi: https://doi.org/10.11606/issn.2179-0892.geousp.2014.81098

BELIZÁRIO, W. da S. Análise ambiental de bacias hidrográficas urbanas: um olhar a partir da avaliação físico-química e microbiológica de águas superficiais. Revista Mirante, Anápolis, v. 9, n. 2, p. 87-116, dez. 2016. Disponível em: <http://www.revist a.ueg.br/index.php/mirante/article/view/5686>.

BENDITO, B. P. C.; SOUZA, P. A. de.; PEREIRA, M. A.; GONÇALVES, D. S. Diagnóstico ambiental e proposição de uso de SAF para área de pastagem degradada. Revista Geoambiente Online, Jataí, n. 29, p. 148-163, jul./dez. 2017. Disponível em: <https://www.revistas.ufg.br/geoambiente/article/ view/42599>. doi: https://doi.org/10.5216/revgeoamb.v0i29.42599

BORGES, L. F. R.; SCOLFORO, J. R.; OLIVEIRA, A. D. de.; MELLO, J. M. de.; ACERBI JUNIOR, F. W. et al. Inventário de fragmentos florestais nativos e propostas para seu manejo e o da paisagem. Revista Cerne, Lavras, v. 10, n. 1, p. 22-38, jan./jun. 2004. Disponível em: <https://www.redalyc.org/articulo.oa?id=74410103>.

CARVALHO, A. C.; CARVALHO, D. F.; FILGUEIRAS, G. C.; ARAÚJO, A. C. de S.; CARVALHO, A. V. de. Panorama e importância econômica do café no mercado internacional de commodities agrícolas: uma análise espectral. Revista Agroecossistemas, v. 9, n. 2, p. 223-249, 2017. Disponível em: <https://periodicos. ufpa.br/index.php/agroecossistemas/article/view/5003/4647>. http://dx.doi.org/10.18542/ragros.v9i2.5003

CARVALHO, T. B. de.; DE ZEN, S. A cadeia de pecuária de corte no Brasil: evolução e tendências. Revista Ipecege, v. 3, n. 1, p. 85-99, 2017. Disponível em: < https://revista.ipecege.com/Revista/article/view/109>. doi: https://doi.org/10.22167/r.i pecege.2017.1.85

CEDAGRO - Centro de Desenvolvimento do Agronegócio. Dimensionamento do mercado capixaba de produtos florestais madeiráveis. Vitória: CEDAGRO, 2011. $15 \mathrm{p}$.

COUTINHO, L. M. Mapeamento de uso do solo e Áreas de Preservação Permanente (APP) na bacia do Córrego Itabira, Cachoeiro de Itapemirim-ES. In: Simpósio Brasileiro de Sensoriamento Remoto, 17., 2015, João Pessoa. Anais... João Pessoa: INPE, 2015. 
COSTA, A. M. S. da.; BEZERRA, P. E. S.; OLIVEIRA, R. S. de. Mudanças no uso e ocupação da terra associadas a focos de calor na área de influência da Rodovia BR163 (Cuiabá-Santarém). Revista Brasileira de Gestão Ambiental, Pombal, v. 11, n. 1, p. 119-125, jan./dez. 2017. Disponível em: <https://www.gvaa.com.br/revista/inde x.php/RBGA/article/view/4956>. doi: https://doi.org/10.18378/rbga.v11i1.4956

DI MAURO, C. A.; MAGESTE, J. G.; LEMES, E. M. As bacias hidrográficas como critério para o planejamento territorial. Revista Caminhos de Geografia, Uberlândia, v. 18, n. 64, p. 472-482, dez. 2017. Disponível em: <http://www.seer.ufu. br/index.php/caminhosdegeografia/article/view/40959>. doi: http://dx.doi.org/10.1439 3/RCG186435

DONATO, L. de P.; MAGRI, R. A. F. Uso e ocupação das áreas de preservação permanente da bacia hidrográfica do córrego do Limão, Passos-MG. Revista Enciclopédia Biosfera, Goiânia, v. 14, n. 25, p. 78-91, 2017. Disponível em: < http://www.conhecer.org.br/enciclop/2017a/agrar/uso\%20e\%20ocupacao.pdf>. doi: 10.18677/EnciBio_2017A101

EMBRAPA. Práticas de conservação do solo e recuperação de áreas degradadas. 1.ed. Rio Branco: Embrapa Acre, 2003. 29 p.

FIORESE, C. H. U.; LEITE, V. R. Dinâmica do uso e cobertura do solo na sub-bacia hidrográfica do ribeirão Estrela do Norte no município de Castelo, estado do Espírito Santo. Agrarian Academy, Goiânia, v. 5, n. 10, p. 52-65, 2018. Disponível em: <http://www.conhecer.org.br/Agrarian\%20Academy/2018B/dinamica.pdf>. $\quad$ doi: 10.18677/Agrarian_Academy_2018B6

FLAUZINO, B. K.; MELLONI, E. G. P.; PONS, N. A. D.; LIMA, O. de. Mapeamento da capacidade de uso da terra como contribuição ao planejamento de uso do solo em sub-bacia hidrográfica Piloto no Sul de Minas Gerais. Revista Geociências, São Paulo, v. 35, n. 2, p. 277-287, 2016. Disponível em: <http://www.ppegeo.igc.usp.br/i ndex.php/GEOSP/article/view/9025/8 290>.

GEOBASES - Sistema Integrado de Bases Geoespaciais do Estado do Espírito Santo. lema - mapeamento ES - 2012-2015. Disponível em: <https://geobases.es. gov.br/links-para-mapes1215>.

INCAPER - Instituto Capixaba de Pesquisa, Assistência Técnica e Extensão Rural. Cafeicultura. Disponível em: <https://incaper.es.gov.br/cafeicultura>.

LIMA, A. R.; GIRARDI, E. P.; MANCIO, D.; NUNES, D. da C. Impactos da monocultura de eucalipto sobre a estrutura agrária nas regiões norte e central do Espírito Santo. Revista NERA, Presidente Prudente, n. 34, p. 12-36, 2016. Disponível em: <http://revista.fct.unesp.br/index.php/nera/article/viewFile/4977/4134>.

LIMA, B. C.; FRANCISCO, C. N.; BOHRER, C. B. de A. Deslizamentos e fragmentação florestal na região serrana do estado do Rio de Janeiro. Revista Ciência Florestal, Santa Maria, v. 27, n. 4, p. 1283-1295, out./dez. 2017. Disponível em: <http://www.scielo.br/pdf/cflo/v27n4/1980-5098-cflo-27-04-1283.pdf>. 
LOPES, P. R.; ARAÚJO, K. C. S.; LOPES, I. A.; RANGEL, R. P.; SANTOS, N. F. de $F$. Uma análise das consequências da agricultura convencional e das opções de modelos sustentáveis de produção - agricultura orgânica e agroflorestal. Revista Espaço de Diálogo e Desconexão, Araraquara, v. 8, n. 1, p. 2014. Disponível em: $<$ https://periodicos.fclar.unesp.br/redd/article/view/6912>. doi: https://doi.org/10.3276 0/1984-1736/REDD/2014.v8i2.6912

MELO, E. B.; PONTES, D. S.; SILVA, V. P. O uso do solo no alto curso da sub-bacia hidrográfica do Rio Preto, Mar Vermelho-AL. Revista Geonorte, v. 10, n. 1, p. 396400, 2014. Disponível em: <http://www.periodicos.ufam.edu.br/revista-geonorte/articl e/view/1582>.

MOLEDO, J. C.; SAAD, A. R.; DALMAS, F. B.; ARRUDA, R. de O. M.; CASADO, F. Impactos ambientais relativos à silvicultura de eucalipto: uma análise comparativa do desenvolvimento e aplicação no plano de manejo florestal. Revista Geociências, São Paulo, v. 35, n. 4, p. 512-530, 2016. Disponível em: <http://ppegeo.igc.usp.br/ind ex.php/GEOSP/article/view/9968/9256>.

OLIVEIRA, D. H. R. de.; ACORSI, M. G.; SMANIOTTO, D. A. Uso e ocupação do solo e caracterização morfométrica de microbacia na região centro-sul paranaense. Águas Subterrâneas - Seção Estudos de Caso e Notas Técnicas, 2018. Disponível em: < https://aguassubterraneas.abas.org/asubterraneas/article/view/291 14>. doi: https://doi.org/10.14295/ras.v32i2.29114

PAULINO, V. T.; SCHUMANN, A. M.; SILVA, S. C. da.; RASQUINHO, N. M.; SANTOS, K. M. dos. Impactos ambientais da exploração pecuária em sistemas intensivos de pastagem. Informe Agropecuário, Belo Horizonte, v. 33, n. 266, p. 714, jan./fev. 2012. Disponível em: < https://www.researchgate.net/profile/Valdinei_Pa ulino/publication/266136785_impactos_ambientais/data/54259a0a0cf2e4ce9403967 b/impactos-ambientais.pdf $>$.

PROCESSAMENTO DIGITAL. Arc GIS 10.2: delimitação de bacias hidrográficas com ArcHydro Tools. Disponível em: <http://www.processamentodigital.com.br/2015/ 03/05/arcgis102-delimitacao-de-bacias-hidrograficas-com-archydro/>.

ROMÃO, E. de P.; PONTES, A. N.; GUTJAHR, A. L. N.; TORRES, W. R. G. Análise temporal do uso e da cobertura do solo nas áreas desflorestadas do município de Altamira, Pará. Revista Enciclopédia Biosfera, Goiânia, v. 14, n. 25, p. 113-126, 2017. Disponível em: <http://www.conhecer.org.br/ enciclop/2017a/agrar/analise\%20 temporal.pdf>. doi: 10.18677/EnciBio_2017A11

SANTOS, A. R. dos.; LOUZADA, F. L. R. de O.; EUGÊNIO, F. C. ArcGis 9.3 total: aplicações para dados espaciais. Alegre: CAUFES, 2010. 184 p.

SILVA, P. J. Uso e ocupação do solo urbano: uma análise dos impactos ambientais nas áreas de dunas no bairro de Felipe Camarão/Natal-RN. Revista Holos, v. 5, p. 91-103, 2015. Disponível em: <http://www2.ifrn.edu.br/ojs/index.php/HOLOS/article/ viewFile/2350/1146>. doi: 10.15628/holos.2015.2350 
VARJABEDIAN, R. Lei da Mata Atlântica: retrocesso ambiental. Revista Estudos Avançados, v. 24, n. 68, p. 147-160, 2010. Disponível em: <http://www.scielo.br/pdf/ ea/v24n68/13.pdf>.

VITAL, M. H. F. Impacto ambiental de florestas de eucalipto. Revista do BNDES, Rio de Janeiro, v. 14, n. 28, p. 235-276, dez. 2007. Disponível em: <http://www.ciflor estas.com.br/arquivos/doc_impacto_eucalipto_12148.pdf>.

ZIMMERMANN, C. L. Monocultura e transgenia: impactos ambientais e insegurança alimentar. Veredas do Direito, Belo Horizonte, v. 6, n. 12, p. 79-100, jul./dez. 2009. Disponível em: <http://domhelder.edu.br/revista/index.php/veredas/article/viewFile/2 $1 / 133>$. 